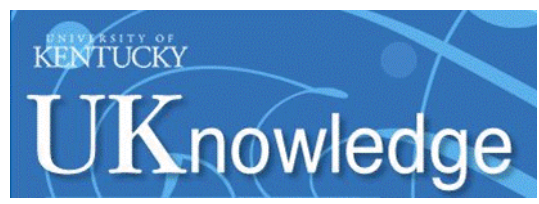

University of Kentucky

UKnowledge

$5-29-2013$

\title{
Compressive Response of Polycrystalline NiCoMnGa High- Temperature Meta-magnetic Shape Memory Alloys
}

\section{H. E. Karaca}

University of Kentucky, karacahaluk@uky.edu

\author{
A. S. Turabi \\ University of Kentucky, sadi.turabi@uky.edu \\ B. Basaran \\ University of Kentucky
}

A. K. Pathak

Southern Illinois University Carbondale

I. Dubenko

Southern Illinois University Carbondale

See next page for additional authors

Follow this and additional works at: https://uknowledge.uky.edu/me_facpub

Part of the Mechanical Engineering Commons

Right click to open a feedback form in a new tab to let us know how this document benefits you.

\section{Repository Citation}

Karaca, H. E.; Turabi, A. S.; Basaran, B.; Pathak, A. K.; Dubenko, I.; Ali, N.; Chumlyakov, Y. I.; and Li, P., "Compressive Response of Polycrystalline NiCoMnGa High-Temperature Meta-magnetic Shape Memory Alloys" (2013). Mechanical Engineering Faculty Publications. 1.

https://uknowledge.uky.edu/me_facpub/1

This Article is brought to you for free and open access by the Mechanical Engineering at UKnowledge. It has been accepted for inclusion in Mechanical Engineering Faculty Publications by an authorized administrator of UKnowledge. For more information, please contact UKnowledge@lsv.uky.edu. 


\section{Compressive Response of Polycrystalline NiCoMnGa High-Temperature Meta- magnetic Shape Memory Alloys}

Digital Object Identifier (DOI)

http://dx.doi.org/10.1007/s11665-013-0593-0

\section{Notes/Citation Information}

Published in Journal of Materials Engineering and Performance, v. 22, no. 10, p. 3111-3114.

Copyright 2013 ASM International. This paper was published in Journal of Materials Engineering and Performance, v. 22, no. 10, p. 3111-3114 and is made available as an electronic reprint with the permission of ASM International. One print or electronic copy may be made for personal use only. Systematic or multiple reproduction, distribution to multiple locations via electronic or other means, duplications of any material in this paper for a fee or for commercial purposes, or modification of the content of this paper are prohibited.

\section{Authors}

H. E. Karaca, A. S. Turabi, B. Basaran, A. K. Pathak, I. Dubenko, N. Ali, Y. I. Chumlyakov, and P. Li 


\title{
Compressive Response of Polycrystalline NiCoMnGa High-Temperature Meta-magnetic Shape Memory Alloys
}

\author{
H.E. Karaca, A.S. Turabi, B. Basaran, A.K. Pathak, I. Dubenko, N. Ali, Y.I. Chumlyakov, and P. Li
}

(Submitted May 31, 2012; in revised form April 7, 2013; published online May 29, 2013)

\begin{abstract}
The effects of the addition of quaternary element, Co, to polycrystalline NiMnGa alloys on their magnetic and shape memory properties have been investigated. NiCoMnGa polycrystalline alloys have been found to demonstrate good shape memory and superelasticity behavior under compression at temperatures greater than $100{ }^{\circ} \mathrm{C}$ with about $3 \%$ transformation strain and low-temperature hysteresis. It is also possible to train the material to demonstrate a large two-way shape memory effect.
\end{abstract}

Keywords intermetallics, magnetic measurements, magnetically ordered materials, martensitic transformations, metals and alloys, shape memory

\section{Introduction}

In recent years, magnetic shape memory alloys (SMAs) are being extensively studied as an alternative to the long-existing magnetostrictives and piezoelectrics in actuator applications. Not only do they possess the ability to display large reversible strains (up to $10 \%$ ) but also the ability to operate at much higher frequencies (up to $\mathrm{kHz}$ range) in comparison with conventional SMAs such as NiTi (Ref 1-4). Depending on the alloying elements, austenite and martensite phases in NiMnbased magnetic SMAs, either both or one, can display ferromagnetism (Ref 5,6).

In NiMnGa alloys, magnetic actuation occurs by variant reorientation of ferromagnetic martensite phase (Ref 2). Drawbacks of NiMnGa alloys are their brittleness, low actuation stress (due to limited magnetic energy), limited operation temperature, and high orientation dependence $(\operatorname{Ref} 2,5)$. Co addition to NiMnGa alloys provides an opportunity to control the Curie temperatures of transforming phases where ferromagnetic austenite can transform to paramagnetic-like martensite (Ref 7,8). Co addition also increases the ductility of the alloy through the formation of ductile second phases (Ref 9).

$\mathrm{NiCoMnGa}$ alloys can be classified as meta-magnetic SMAs (like NiMnCoIn alloys) where magnetic field-induced phase transformation may result in one order of higher actuation stress

H.E. Karaca, A.S. Turabi, and P. Li, Department of Mechanical Engineering, University of Kentucky, Lexington, KY 40506; B. Basaran, Department of Mechanical Engineering, University of Kentucky, Lexington, KY 40506; and University of Turkish Aeronautical Association, Ankara 06790, Turkey; A.K. Pathak, I. Dubenko, and N. Ali, Department of Physics, Southern Illinois University, Carbondale, IL 62901; and Y.I. Chumlyakov, Siberian Physical-Technical Institute, Tomsk State University, Tomsk 634050, Russia. Contact e-mail: karaca@engr.uky.edu.

than that of variant reorientation in NiMnGa alloys. Owing to their brittleness and orientation dependence of Magnetocrsytalline anisotropy energy, mostly single crystalline NiMnGa alloys can be utilized for practical applications. On the other hand, meta-magnetic SMAs, e.g., $\mathrm{NiMn}(\mathrm{In}, \mathrm{Sn}, \mathrm{Sb})$ alloys, can be utilized in polycrystalline form since Zeeman Energy does not depend on orientation, and they have the ability to achieve very high actuation stress levels via field-induced phase transformations (Ref 5). However, they require high magnetic fields (4 $\mathrm{T}$ and up) to realize reversible phase transformation (Ref 5,6$)$. The critical field can be reduced by diminishing thermal hysteresis or by increasing the difference between saturation magnetizations of the transforming phases. Hysteresis is also a strong function of applied stress and should be characterized before utilizing these materials as magnetic actuators.

Although the effects of Co addition on the transformation temperatures (TTs) and magnetic properties of $\mathrm{NiCoMnGa}$ are reported, there have been limited studies on their conventional shape memory behavior. This partly stems from the extreme brittleness of NiMnGa alloys where there is very limited mechanical testing data in its polycrystalline form (Ref 10). To the author's knowledge, only the room temperature mechanical behavior of NiCoMnGa alloys has been reported so far (Ref 9, 11). In order to determine their potential as meta-magnetic SMAs, it is very important to know their conventional shape memory behavior. Current study aims to investigate the effects of Co addition to polycrystalline NiCoMnGa alloys on not only their magnetic properties but also their shape memory properties under compression.

\section{Experimental Procedure}

Polycrystalline specimens with chemical compositions $\mathrm{Ni}_{50-x} \mathrm{Co}_{x} \mathrm{Mn}_{32} \mathrm{Ga}_{18}$ (at.\%) $x=0,4,6,7,8$ were prepared by conventional arc melting method in an argon atmosphere using high-purity elements such as Ni (99.9\%); Mn (99.99\%); Co $(99.9 \%)$; and Ga $(99.999 \%)$. Then, the arc melted buttons were annealed at $850{ }^{\circ} \mathrm{C}$ for $72 \mathrm{~h}$ under vacuum and slowly cooled down to room temperature in the furnace. TTs are determined by differential scanning calorimetry (DSC) (Perkin 
Elmer Pyris1), and magnetization properties are measured by superconducting quantum interference device magnetometer (SQUID) (Quantum Design, Inc.). The thermomechanical experiments were conducted on $2 \times 2 \times 4 \mathrm{~mm}^{3}$ compression samples by means of MTS Landmark servohydraulic test frame retrofitted with a PID-controlled heating/cooling assembly. Strain measurements were attained by mwans of a hightemperature capacitive displacement sensor (Capacitec Inc.).

\section{Results and Discussion}

Figure 1 shows the magnetization response of $\mathrm{Ni}_{42}$ $\mathrm{Co}_{8} \mathrm{Mn}_{32} \mathrm{Ga}_{18}$ alloy as a function of temperature. The sample is cooled down to $5 \mathrm{~K}$ under zero magnetic field and $0.1 \mathrm{~T}$ is applied, then it is heated up to $400 \mathrm{~K}$ and cooled down to $5 \mathrm{~K}$ under $0.1 \mathrm{~T}$. During heating, ferromagnetic martensite becomes paramagnetic like greater than $300 \mathrm{~K}$, and transforms to ferromagnetic austenite greater than $380 \mathrm{~K}$. Upon cooling, ferromagnetic austenite transforms to paramagnetic martensite initially, and then follows a magnetic transition where martensite becomes ferromagnetic. No thermal hysteresis is observed during magnetic transition in martensite phase, while the first-order austenite-to-martensite phase transformation is associated with a thermal hysteresis of about $20 \mathrm{~K}$. When the sample is heated from $5 \mathrm{~K}$ to $400 \mathrm{~K}$ under $5 \mathrm{~T}$, its magnetization increases, and martensite-to-austenite TT decreases by $19 \mathrm{~K}$ compared to that under $0.1 \mathrm{~T}$.

Shift of TTs to lower temperature with applied field is a characteristic behavior observed in meta-magnetic SMAs and termed as austenite stabilization (Ref 5). Reversible fieldinduced phase transformation becomes possible if TTs decrease to a level where the martensite finish temperature under zero field is higher than the austenite finish temperature under applied field. In general, thermal hysteresis does not change considerably with applied field. Thus, the critical field for reversible field-induced phase transformation decreases with hysteresis. It has been found that (not shown in Fig. 1) Curie temperatures of martensite, $T_{\mathrm{CM}}$, of $\mathrm{Ni}_{50-x} \mathrm{Co}_{x} \mathrm{Mn}_{32} \mathrm{Ga}_{18}$ alloys decrease with increase in Co content from $315 \mathrm{~K}$ to $290 \mathrm{~K}$ for $x=0$ and $x=8$, respectively.

When martensite is ferromagnetic, field-induced strain can be obtained by variant reorientation, provided detwinning stress is low and the magnetocrystalline anisotropy energy is high.

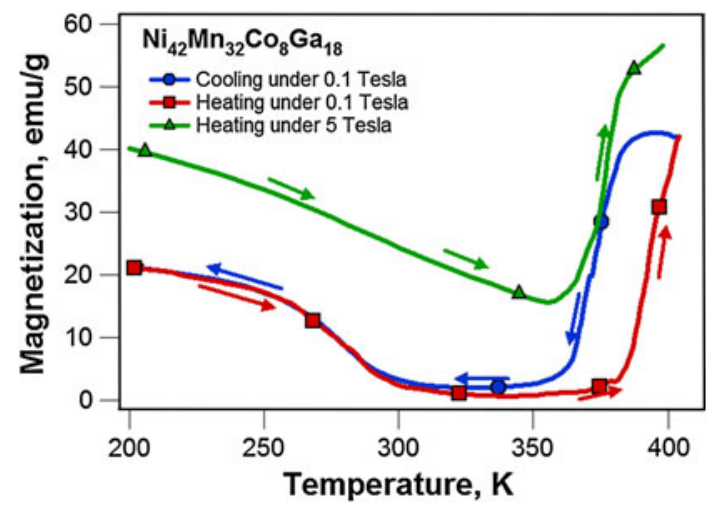

Fig. 1 Magnetization response of $\mathrm{Ni}_{42} \mathrm{Co}_{8} \mathrm{Ga}_{18} \mathrm{Mn}_{32}$ alloy as a function of temperature under 0.1 and $5 \mathrm{~T}$ fields
When the alloy is meta-magnetic, field-induced strain can be obtained through phase transformation. Therefore, in NiCoMnGa alloys, while field-induced strain might be obtained through variant reorientation at lower temperatures, it could be realized by phase transformation at higher temperatures.

Figure 2 shows the DSC response of $\mathrm{Ni}_{50-x} \mathrm{Co}_{x} \mathrm{Mn}_{32} \mathrm{Ga}_{18}$ $(x=0,4,6,7,8)$ alloys. During cooling, the exothermic peak corresponds to austenite-to-martensite transformation. Upon heating, martensite transforms back to austenite. TTs are determined to be greater than $100{ }^{\circ} \mathrm{C}$ which makes them qualify as high-temperature SMAs. TTs slightly increase with Co addition up to $6 \%$ and then decrease. Peak thermal hysteresis is about $20^{\circ} \mathrm{C}$ for all the alloys, and it is consistent with magnetization results.

Figure 3(a) and (b) demonstrates the isobaric thermal cycling responses of $\mathrm{Ni}_{50} \mathrm{Ga}_{18} \mathrm{Mn}_{32}$ (Co-free) and $\mathrm{Ni}_{44} \mathrm{Co}_{6}$ $\mathrm{Mn}_{32} \mathrm{Ga}_{18}$ (Co-doped) alloys, respectively, as a function of applied stress. The samples were loaded to selected stress levels (increased incrementally up to $200 \mathrm{MPa}$ ) greater than their austenite finish temperature $\left(A_{\mathrm{f}}\right)$ and thermally cycled between a temperature less than martensite finish temperature $\left(M_{\mathrm{f}}\right)$ and a temperature greater than $A_{\mathrm{f}}$. At the end of the cycle, applied stress is increased to next level, and thermal cycling is repeated.

As temperature decreases, certain martensite variants grow along the applied stress increasing the detected strain. Upon heating, they transform back to austenite. It is clear that the transformation occurs greater than $100{ }^{\circ} \mathrm{C}$ which is in good agreement with DSC results. Compressive strain increases initially because of increased volume fraction of oriented variants and then saturates with stress. Temperature hysteresis shows a similar trend to the transformation strain. Temperature hysteresis of $\mathrm{Ni}_{50} \mathrm{Ga}_{18} \mathrm{Mn}_{32}$ is determined to be $19{ }^{\circ} \mathrm{C}$ under $50 \mathrm{MPa}$ which is consistent with DSC and SQUID results. Temperature hysteresis increases from 19 to $32{ }^{\circ} \mathrm{C}$ as the applied stress increases from 15 to $200 \mathrm{MPa}$. It should be kept in mind that the higher the hysteresis, the higher the required magnetic field for reversible transformation. The transformation strains are 1.2 and $1.7 \%$ under $50 \mathrm{MPa}$ and 2.4 and $2.9 \%$ under

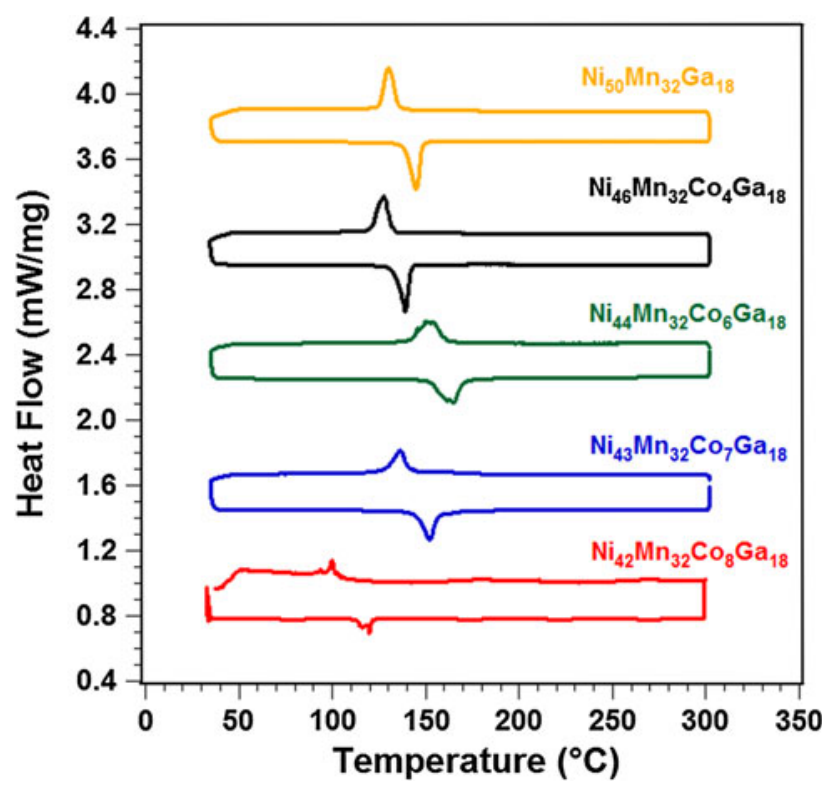

Fig. 2 A comparison of DSC results showing the effect of Co doping on TTs of $\mathrm{Ni}_{50-x} \mathrm{Co}_{x} \mathrm{Ga}_{18} \mathrm{Mn}_{32}(x=0,4,6,7,8)$ alloys 

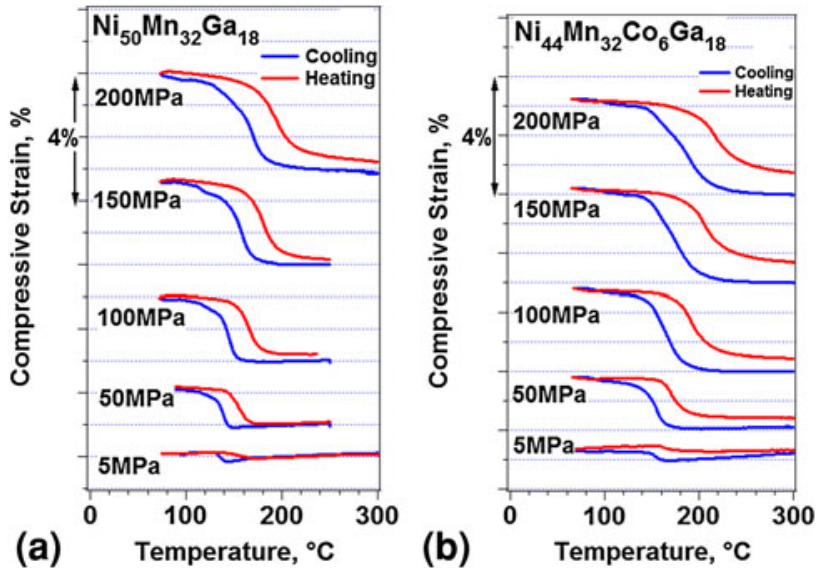

Fig. 3 Shape memory behavior of (a) $\mathrm{Ni}_{50} \mathrm{Ga}_{18} \mathrm{Mn}_{32}$ and (b) $\mathrm{Ni}_{44} \mathrm{Co}_{6} \mathrm{Ga}_{18} \mathrm{Mn}_{32}$ alloys under compression

$200 \mathrm{MPa}$ for the $\mathrm{Ni}_{50} \mathrm{Ga}_{18} \mathrm{Mn}_{32}$ and $\mathrm{Ni}_{44} \mathrm{Co}_{6} \mathrm{Ga}_{18} \mathrm{Mn}_{32}$ alloys, respectively.

Irrecoverable strain increases with stress because of more pronounced generation of defects and dislocations at higher stress levels. The Co-free specimen showed full recovery up to $100 \mathrm{MPa}$; however, Co-doped specimens displayed a monotonously increasing trend in irrecoverable strain with increasing applied stress starting at $50 \mathrm{MPa}$. The amount of plastic strain of the Co-doped specimen increased from 0.35 to $0.8 \%$ when applied stress is increased from 50 to $200 \mathrm{MPa}$. This tendency might be due to the ductile gamma phase that occurs upon Co addition which was reported to hamper reorientation or detwinning of the martensite variants as well as promote defect generation such as dislocations (Ref 12). Formation of second phases might also be responsible for the change of the shape of cooling curves as the transformation progresses. While the Co-doped alloy demonstrates a smoother and more symmetrical transition, the Co-free specimen displays a sharper curve (almost like a corner) indicating a faster (burst-type) transition. Smoother curve might be attributed to the increased elastic energy stored in the material due to the interaction of phase front with second phase or particles.

Figure 4 shows the superelastic behavior of Co-free and Co-doped specimens greater than their $A_{\mathrm{f}}$. Upon loading, austenite transforms to martensite and martensite transforms back to austenite during unloading. Near-perfect superelasticity is observed with a total strain of $3 \%$ at 170 and $180{ }^{\circ} \mathrm{C}$ for Co-free and $3.5 \%$ at 180 and $200{ }^{\circ} \mathrm{C}$ for Co-doped samples. As evidenced by the fact that at the end of loading, the level of applied stress reaches a maximum of $290 \mathrm{MPa}$, this alloy possesses fair strength for fracture.

Figure 5 shows the two-way shape memory effect (TWSME) in Co-doped and Co-free alloys. The samples were cooled down before (untrained) and after (trained) the tests shown in Fig. 4 and 5 under $5 \mathrm{MPa}$. $5 \mathrm{MPa}$ is applied to keep the grips in contact with the specimen for strain measurements. It is clear that after training, both alloys demonstrated more than 3\% transformation strain upon cooling, while it was about $0.2 \%$ before training. The high transformation strain upon training indicates that internal stress fields to select certain martensite variants upon transformation are formed upon training. This is a very useful tool to observe strain during field-induced phase transformations. Since martensite is nonmagnetic, there is no driving force for the selection of variants

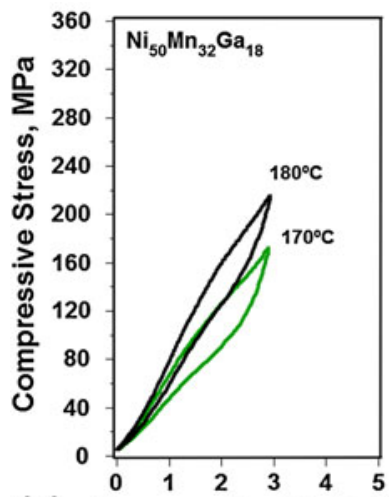

(a) Compressive Strain, \%

Fig. 4 Superelasticity behaviors (b) $\mathrm{Ni}_{44} \mathrm{Co}_{6} \mathrm{Ga}_{18} \mathrm{Mn}_{32}$ (at.\%) alloys

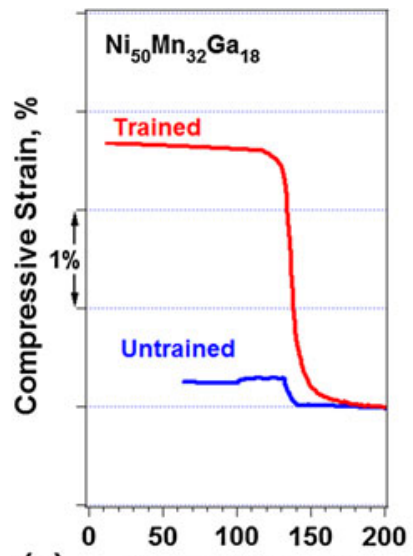

(a) Temperature, ${ }^{\circ} \mathrm{C}$

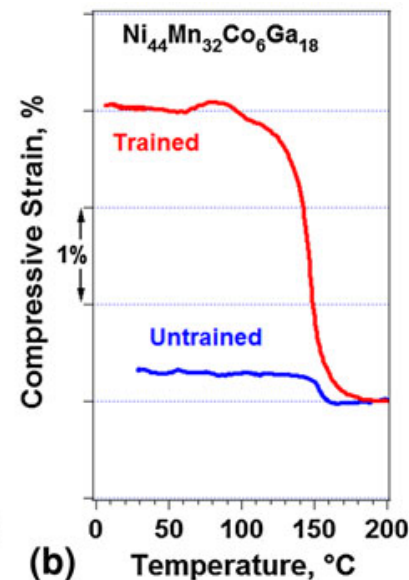

Fig. 5 TWSME behaviors under $5 \mathrm{MPa}$ of (a) $\mathrm{Ni}_{50} \mathrm{Ga}_{18} \mathrm{Mn}_{32}$ and (b) $\mathrm{Ni}_{44} \mathrm{Co}_{6} \mathrm{Ga}_{18} \mathrm{Mn}_{32}$ alloys in untrained and trained conditions

during field-induced phase transformation. However, if the material can be trained, then austenite will transform to martensite with selected variants that will result in macroscopic strain.

\section{Conclusions}

It has been found that NiCoMnGa alloys can be utilized as both meta-magnetic and high-temperature SMAs in their polycrystalline form. NiCoMnGa alloys demonstrate good shape memory behavior under stress levels up to $200 \mathrm{MPa}$ in polycrystalline form and can also be classified as hightemperature SMAs with perfect superelasticity greater than $150{ }^{\circ} \mathrm{C}$. They can also be trained easily to show good TWSME that would result in high strain upon field-induced transformations.

\section{Acknowledgments}

The authors gratefully acknowledge the financial support from National Science Foundation (NSF) CMMI Award \#0954541. Financial support for a student researcher was provided by the KY 
NSF EPSCoR Program and NSF Award \#0814194. This study at SIUC was supported by the Office of Basic Energy Sciences, Material Sciences Division of the U.S. Department of Energy (Contract No. DE-FG02-06ER46291).

\section{References}

1. O. Heczko, A. Sozinov, and K. Ullakko, Giant Field-Induced Reversible Strain in Magnetic Shape Memory NiMnGa alloy, IEEE Trans. Magn., 2000, 36(5), p 3266-3268

2. H.E. Karaca, I. Karaman, B. Basaran, Y.I. Chumlyakov, and H.J. Maier, Magnetic Field and Stress Induced Martensite Reorientation in NiMnGa Ferromagnetic Shape Memory Alloy Single Crystals, Acta Mater., 2006, 54(1), p 233-245

3. S.J. Murray, M. Marioni, S.M. Allen, R.C. O'Handley, and T.A. Lograsso, 6\% Magnetic-Field-Induced Strain by Twin-Boundary Motion in Ferromagnetic Ni-Mn-Ga, Appl. Phys. Lett., 2000, 77(6), p 886-888

4. A. Sozinov, A.A. Likhachev, N. Lanska, and K. Ullakko, Giant Magnetic-Field-Induced Strain in NiMnGa Seven-Layered Martensitic Phase, Appl. Phys. Lett., 2002, 80(10), p 1746

5. H.E. Karaca, I. Karaman, B. Basaran, Y. Ren, Y.I. Chumlyakov, and H.J. Maier, Magnetic Field-Induced Phase Transformation in NiMnColn Magnetic Shape-Memory Alloys-A New Actuation Mechanism with Large Work Output, Adv. Funct. Mater., 2009, 19(7), p 983-998
6. R. Kainuma, Y. Imano, W. Ito, Y. Sutou, H. Morito, S. Okamoto, O. Kitakami, K. Oikawa, A. Fujita, T. Kanomata, and K. Ishida, Magnetic-Field-Induced Shape Recovery by Reverse Phase Transformation, Nature, 2006, 439(7079), p 957-960

7. S. Fabbrici, F. Albertini, A. Paoluzi, F. Bolzoni, R. Cabassi, M. Solzi, L. Righi, and G. Calestani, Reverse Magnetostructural Transformation in Co-Doped NiMnGa Multifunctional Alloys, Appl. Phys. Lett., 2009, 95(2), p 022508

8. V. Sanchez-Alarcos, J.I. Perez-Landazabal, V. Recarte, C. Gomez-Polo, and J.A. Rodriguez-Velamazan, Correlation Between Composition and Phase Transformation Temperatures in Ni-Mn-Ga-Co Ferromagnetic Shape Memory Alloys, Acta Mater., 2008, 56(19), p 5370-5376

9. Y.Q. Ma, S.Y. Yang, Y. Liu, and X.J. Liu, The Ductility and ShapeMemory Properties of Ni-Mn-Co-Ga High-Temperature Shape-Memory Alloys, Acta Mater., 2009, 57(11), p 3232-3241

10. H. Morawiec, T. Goryczka, J. Lelatko, K. Prusik, and A. Drdzeń, Effect of Deformation on Structure and Mechanical Behavior of Polycrystalline Ni-Mn-Ga Alloys, Eur. Phys. J. Special Top., 2008, 158(1), p 93-98

11. D.Y. Cong, S. Wang, Y.D. Wang, Y. Ren, L. Zuo, and C. Esling, Martensitic and Magnetic Transformation in Ni-Mn-Ga-Co Ferromagnetic Shape Memory Alloys, Mater. Sci. Eng. A, 2008, 473(1-2), p 213-218

12. S.Y. Yang, Y.Q. Ma, H.F. Jiang, and X.J. Liu, Microstructure and Shape-Memory Characteristics of $\mathrm{Ni}(56) \mathrm{Mn}(25-x) \mathrm{Co}(x) \mathrm{Ga}(19)$ $(x=4,8)$ High-Temperature Shape-Memory Alloys, Intermetallics, 2011, 19(2), p 225-228 